\title{
INTERVIEW
}

\section{Optimising Classroom Interaction: An Interview with Steve Walsh}

\author{
Vanesa Fernández del Viso Román \\ Universitat Autònoma de Barcelona, Barcelona, Spain \\ (Text received 24 November 2012; final version received 3 December 2012)
}

\begin{abstract}
Professor Steve Walsh is Professor of Applied Linguistics at the School of ECLS of the University of Newcastle in the United Kingdom. He is the module leader for 'Teacher Development for TESOL', 'Learning and teaching in Higher Education', 'Discourse Analysis for English language teachers'. He also supervises Mlevel and Doctoral students. His main research interests focus on all aspects of classroom discourse and the interactional awareness among both teachers and pupils. He has published articles in journals such as Language Teaching Research, Corpus Linguistics and Linguistic Theory, ELT Journal and Language Awareness and books that have made an important impact on research in classroom interaction, such as Investigating Classroom Discourse (2006), and Exploring Classroom Discourse: Language in action (2011).
\end{abstract}

INTERVIEWER: Thank you, Dr. Walsh for agreeing to being interviewed. I have seen from your work that you propose that making pupils interact in the lessons is an optimal way of maximizing their learning processes for their own development. However, for many teachers, reality dictates that students need a clear map of where they are going in their learning process and to know what is expected of them. Clearly they also need to know the final point of the communication process. This brings up a few questions that I hope you can help clarify for our readers. The first one is: In your proposal of classroom interaction, does this imply that students are not led by the teacher in the type of interaction they engage in?

STEVE WALSH: No, not at all. I think there are two things here. There is a thing called 'planfulness' and there is a thing called 'spontaneity' in any teaching. So, you need both; you need to have a sense of where you are going and I agree that students need to know, you know, what they have done, what comes next and so on. That is one side of this and it's obviously very important, but there is also an important aspect that is what I call 'online decisions-making'. Teachers make decisions in the moment and those 
decisions create opportunities or they can actually obstruct opportunities. And I think that what is most important is how teachers make their decisions so that interaction that will allow learners to participate. For instance, if we are interrupting them, then we are not giving them the chance to participate. In other words, we have got 'planfulness' on the one hand, which is what goes on before we teach. But, while teachers are actually working with a group, they make interactive decisions online and it is those decisions which can create opportunities for learning or obstructing them. I'll give you example, imagine where, I don't know, students are having a discussion about, say American politics, and as a learner, you say something like, ah ... 'yeah, he should've, ought to have done that' and I correct you and I say 'you mean he should have done that' and I give a long, long grammar explanation and we are losing the moment there for discussion, we are actually spending a long time on something which could have been done very quickly. Those crucial decisions, which are not planned and in any way practiced, take place in the moment and I think that is what I am saying in the 2006 and 2011 books. It is about how to make teachers more aware of making good interactive decisions.

INTERVIEWER: Right.

STEVE WALSH: Those are decisions which create opportunities for learning.

INTERVIEWER: In the lectures and talks you gave while you were here at the UAB, you mentioned that language teaching methodology courses need to be revised because there is an important strand of research/application that is missing which is classroom interactional competence. Can you tell a bit more about this and how do you foresee this strand being developed? How can we help teachers learn to make those right decisions you said?

STEVE WALSH: So, basically classroom interaction is to do with the ways in which we create opportunities for learning, which are not based on the methodology or the materials. But they are based on the interaction which takes place. Going back to your original point, Teacher Education programmes at the moment have two strands: one strand which is Subject Knowledge and one strand which is Methodology or Pedagogy or something like that. This third strand is not Methodology-based decisions or 
Curriculum decisions. It is all about the ways in which we interpret or respond to students' answers. That is to say, it is the way we take the response from a student and what we do with that response. I call it 'shaping'. So, you say something and the feedback I give to this response is extremely important for the learning that takes place. So, I can open things up or I can close things down; that's a very basic things. I could say "Yes, Well-done!", "Good answer" or I can try to solicit a longer response. Those are the skills that we need to teach and those skills that teachers need to be good at, and what I mean is that although some teachers are almost natural at doing that, that are some who don't know how to do it. So, what we need to do is just looking at their own data, recordings, listening to themselves teaching -not just transcribing-, but actually just doing short recordings of 15 minutes and analyzing the recordings in terms of 'am I creating opportunities for learning or am closing them down?', how do I respond when I get an answer. Do I always just say "great", "thank you”, “excellent” or I open it up in some way? That is what I mean by 'classroom-interaction'; of course this is extremely context specific. So, what may work in a Primary school in Barcelona will be totally different from a Private language school in this country for adults. It is completely out of context.

INTERVIEWER: I think that's related to another one of the other questions I have. You point out that the interaction in class is a key element in the student process in order for the learner to become proficient in a language. This communication competence builds the students' knowledge and their critical thinking. But, for example in Spain, the government is reducing the number of teachers in all schools and currently we may have more or less 34 students per class. Do you think that classes of this size can still be managed to maximize learning opportunities of this type you are proposing? Do you think effective interaction can still be set up with more than thirty students in a lesson?

STEVE WALSH: Yes, I do. That is probably a situation which is in many parts of the world; that is not unique to Barcelona or Spain. I think it is more difficult. Obviously with a small group you can do more, but that does not mean to say that you can't, for example, look at the ways in which students participate. Participation is a key element for the learning process. One of the things that we try to create is what is called 'dialogic teaching' where teaching is essentially a conversation. So, when we have a conversation in the classroom is not a conversation between the teacher and one student, 
it is between the teacher, one student and the whole class. They need to be involved in some way. And If it's one teacher to one student, how do you involve the rest of the class, what are they doing to interact? It is about getting students engaged in this dialogue, even if I am talking to you, the rest of the class needs to listen and be ready to comment.

INTERVIEWER: Yeah.

STEVE WALSH: So what I are trying to propose in a class of 30 or 35 students is an understanding of multi-party talk. How does the interaction between a teacher and one student relate to the rest of the class? How can they gain? It is a bit like a debate with an audience where there is a main panel of people talking to each other. How would you involve your audience to discussion? This is the trick. It takes a lot of planning before you are going to class and a lot of, I think, mental agility on the part of the teacher to be able to respond to things quickly and include the views and opinions of other people in the group. But, you know, a lot of this is about managing expectations and I think teachers could do more to manage expectations differently. In the sense, I think that when you are going to classroom as a student, there is still this feeling that the teacher asks the questions and I answer them because that is my role. I think we need to shift that a little bit and say that this is only about conversation and in any conversation we all want to play our part, you know, we all have something to contribute. So it's about setting things up in such a way that students have the expectation that I, as a teacher, would expect you to be involved and participate, contribute, that is, take part in the discussion. In short, I think this is really how learning takes place.

INTERVIEWER: In many times, teachers are unwilling to accept that students can learn without their help; they believe that it has to be teacher-fronted situations. How can teachers overcome this fear of not controlling the exact type of input that is taking place and the exact type of output, as well because obviously, in the moment when you open you this up to dialogic interaction, you no longer control it. How can you be sure that you get the objectives of the lesson, that you meet and cover the content that it is required in the Curriculum? This is one of the biggest worries of the teachers who are not used to this type of teaching. So, could you give us some pointers perhaps? 
STEVE WALSH: This is all about doing it in small steps; taking it in one step a time. For example, maybe the first step is to give the group something to think about and talk about in small groups or in pairs, and to give them the chance to rehearse their answer before we go public. So you do it this way. You can tell the students "Here is a question for you, you have 5 minutes and think about this in your groups and then I want to hear your opinions on this". In that way, the teacher is controlling not only the content of what they are talking about but also giving them a little bit of rehearsal time, so they can plan what they want to say and give their responses. You know, it's that kind of incremental approach rather than changing everything overnight and I think that is what teachers need to do, you have got to feel comfortable as a teacher, you can't change if it does not feel right. To make that happen, I think, we need to do it very gradually and over a period of time, giving more and more control of the floor to the students and taking more and more the backseat. Eventually what we want to have is students interacting with each other across the curriculum, across the classroom and everybody joining in. Then, the teacher is a kind of shaper. Your job is to monitor this, guide the discussion. I do think it takes a lot of different skills to the ones that we are currently training in those Teaching Education programmes. We do not train those skills very much, we assume that by teaching that teachers would acquire them and that is not always the case, you know.

INTERVIEWER: This seems to be mostly focused on oral competence which is obviously according to the European Framework as one of the ones being most promoted, if you like, do you see a way of integrating the other competences in the same dialogic fashion, such as writing skills or reading skills?

STEVE WALSH: I think that the answer is to integrate them anywhere. I do not think skills should not be taught in isolation. When we are speaking our own language, we never use only one skill. For example, I am talking and listening to you right now and I am also looking at things around me, you know, seeing what is coming up next in my diary. So, I'm doing that kind of thing is the way, I think, skills need to be taught. One of the things about 'dialogic teaching' is that it requires what Professor Michael McCarthy calls 'listenership'. So, this is not the same as listening. it is the attention that the listener gives a speaker to show understandings on nodding your head and you smiling. Things like that which tell me that you understand me and I can continue. Now, 
I don't think that has been taught anywhere. But it is not just that, it is also things like discussing with little words like "yes", "ok", "fine" or "I am sorry, I didn't get that" and you are breaking up there. We rely on this feedback from our conversation partner in order to speak fluently. So, I think one of the things about fluent speech is that we need to train skills in listening.

Just to finish this question, writing a good one - where a lot of the preparation can be dialogic and I think there's evidence shows the quality of the writing improves a lot when a fair amount of time is spent, again, rehearsing orally before we try to write it down. For example, in my own writing I know that if I talked things through first, and I get feedback; it really helps me when I start to write it down.

INTERVIEWER: Thank you very much for your time and your availability.

STEVE WALSH: You're welcome.

\section{References:}

Walsh, S. (2006). Investigating classroom discourse. Milton Park: UK/New York: NY. Walsh, S. (2011). Exploring classroom discourse: Language in action. Milton Park: UK/New York: NY.

\footnotetext{
Author References:

Vanesa Fernández del Viso Román has a Master in Education from the Department of Language and Literature Education, Universitat Autònoma de Barcelona (Spain), where she carried out research on Project-Based Language Learning (PBLL) applied to teaching Shakespeare to secondary students in an English as a Foreign Language (EFL) classroom. She teaches English and is head of Foreign Language studies at a secondary school in Catalonia.

Email: vanesa.fernandezd@e-campus.uab.cat

To cite this article:

Fernández del Viso Román, V. (2012) Optimising classroom interaction: An interview with Steve Walsh. Bellaterra Journal of Teaching \& Learning Language \& Literature, 5(4), 69-74.
} 